\title{
A Qualitative Study on Incentives and Disincentives for Care of Common Mental Disorders in Ontario Family Health Teams
}

\author{
Rachelle Ashcroft, Jose Silveira, and Kwame McKenzie

\begin{abstract}
Version Published Version/Final PDF
Citation Ashcroft R, Silveira J, McKenzie K. A Qualitative Study on Incentives (published version) and Disincentives for Care of Common Mental Disorders in Ontario Family Health Teams. Healthcare Policy. 2016;12(1):84-96. doi: 10.12927/hcpol.2016.24778
\end{abstract}

Copyright/Licence CC BY-NC 3.0

How to cite TSpace items

\begin{abstract}
Always cite the published version, so the author(s) will receive recognition through services that track citation counts, e.g. Scopus. If you need to cite the page number of the author manuscript from TSpace because you cannot access the published version, then cite the TSpace version in addition to the published version using the permanent URI (handle) found on the record page.
\end{abstract}

This article was made openly accessible by $U$ of $T$ Faculty. Please tell us how this access benefits you. Your story matters. 


\title{
A Qualitative Study on Incentives and Disincentives for Care of Common Mental Disorders in Ontario Family Health Teams
}

\section{Étude qualitative des mesures incitatives et de dissuasion dans les équipes Santé familiale ontariennes pour les soins pour les troubles mentaux les plus courants}

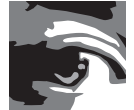 \\ RACHELLE ASHCROFT, PHD \\ Assistant Professor, Factor-Inwentash Faculty of Social Work \\ University of Toronto \\ Toronto, ON \\ JOSE SILVEIRA, MD \\ Chief of Psychiatry, Medical Director, Mental Health and Addiction Program, St. Joseph's Health Centre \\ Assistant Professor, Department of Psychiatry, University of Toronto \\ Toronto, ON \\ KWAME MCKENZIE, MD \\ CEO of Wellesley Institute \\ Medical Director Health Equity, Centre for Addiction and Mental Health \\ Professor, Department of Psychiatry, University of Toronto \\ Toronto, ON
}

\begin{abstract}
Background: An opportunity to address the needs of patients with common mental disorders (CMDs) resides in primary care. Barriers are restricting availability of treatment for CMDs in primary care. By understanding the incentives that promote and the disincentives that deter treatment for CMDs in a collaborative primary care context, this study aims to help contribute to goals of greater access to mental healthcare.

Method: A qualitative pilot study using semi-structured interviews with thematic analysis. Results: Participants identified 10 themes of incentives and disincentives influencing quality treatment of CMDs in a collaborative primary care setting: high service demands,
\end{abstract}


clinical presentation, patient-centred care, patient attributes, education, physician attributes, organizational, access to mental health resources, psychiatry and physician payment model. Conclusion: An understanding of the incentives and disincentives influencing care is essential to achieve greater integration and capacity for care for the treatment of CMDs in primary care.

\section{Résumé}

Contexte: Les soins de santé primaires offrent l'occasion de répondre aux besoins des patients souffrant des troubles mentaux les plus courants (TMC). Il y a, dans les soins primaires, des obstacles qui restreignent la disponibilité de traitements pour les TMC. En cherchant à mieux comprendre les mesures incitatives qui favorisent les traitements ainsi que les moyens de dissuasion qui y font obstacle dans un contexte de soins primaires en collaboration, cette étude entend contribuer à l'atteinte des objectifs d'accès aux traitements pour les maladies mentales.

Méthode : Étude qualitative pilote qui fait appel à des entrevues semi-dirigées et à l'analyse thématique. Résultats: Les participants ont dégagé dix thèmes de mesures incitatives et de dissuasion qui influencent la qualité des traitements pour les TMC dans un établissement de soins primaires en collaboration : demande élevée de services, tableau clinique, soins axés sur les patients, attributs des patients, éducation, attributs des médecins, organisation, accès aux ressources en santé mentale, psychiatrie et modèle de rétribution des médecins.

Conclusion: La compréhension des mesures incitatives et de dissuasion qui influent sur les soins est essentielle pour atteindre une plus grande intégration et une meilleure capacité pour le traitement des TMC dans le contexte des soins primaires.

\section{Introduction}

Depression and anxiety, also referred to as common mental disorders (CMDs), are two of the leading mental health causes of disability and a major cause of mortality (Ferrari et al. 2013; Katzman et al. 2014; Lepine and Briley 2011). The greatest opportunity to address the needs of patients with CMDs resides in primary care (Craven and Bland 2013; Cuijpers et al. 2012; Jenkins and Strathdee 2000; Mohamoud et al. 2012). Several authors have argued that important barriers to the optimal prevention and management of CMDs in Canadian primary care services lie in the misaligned incentive systems currently in place (Dewa et al. 2001; Durbin et al. 2016; Mulvale et al. 2008; Rush et al. 2013; Steele et al. 2013).

A systematic pan-Canadian primary care reform began in the early 2000s (Hutchison et al. 2011). Key reform objectives included promoting population-based service delivery, shifting from a disease-focused and problem-based approach to a patient-centred preventive care orientation, improving access to care and facilitating integration across different services (Hutchison et al. 2011). In Ontario, three main trends can be distinguished. The first is a shift away from the fee-for-service based remuneration to a capitation-based system where the main component of the physician compensation is based on the number of (age-and sex-adjusted) patients under their care and is largely dissociated from the actual number of services rendered to these patients (Hutchison 
and Glazier 2013; Hutchison et al. 2011). The second is patient enrolment to individual physicians, intended to promote continuity and patient-centred care. The third was the transformation of some practices (most of which function under a capitation-based system) into interprofessional teams called Family Health Teams (FHTs) (Hutchison and Glazier 2013; Hutchison et al. 2011).

FHTs are one primary care model in Ontario implemented in 2005, intended to help address the treatment gap for CMDs by building capacity and improving access to mental health services (Ontario Ministry of Health and Long-Term Care [MOHLTC] 2005). FHTs bring family physicians together with healthcare providers - nurses, social workers, pharmacists and others - to provide interdisciplinary team-based care (MOHLTC 2005). FHTs are intended to be a flexible model resulting in variation between them in terms of the type and the number of healthcare providers. Despite the intention, barriers continue to deter integration of mental healthcare services in FHTs (Ashcroft 2014; MOHLTC 2014; Pottie et al. 2008).

Incentives and disincentives are used in the design of healthcare systems to help guide the desired goals (Biller-Andorno and Lee 2013; Conrad 2010). An incentive refers to a motivator that encourages the action of professionals, teams and organizations (Conrad 2010; Custers et al. 2008). A disincentive can be something that operates as an intentional or unintentional deterrent that discourages action (Ashcroft et al. 2014; Enjolras 1999). Understanding incentives that promote and the disincentives that deter treatment for CMDs in primary care will help to achieve goals of greater access to mental healthcare (Craven and Bland 2013; MOHLTC 2014). The objective of this study is to identify factors that help promote or deter the treatment of CMDs in FHTs located in Toronto, Canada. Consequently, this study helps provide an understanding of incentives and disincentives that are contextually relevant to a new model of team-based primary care.

\section{Method}

The setting for this study was FHTs located in Toronto, Canada. An exploratory qualitative design was used (Miles and Huberman 1994) and the study population was composed of physicians practising in FHTs. Research Ethics Board Approval was obtained for this study through the Centre for Addiction and Mental Health (CAMH) located in Toronto, Ontario. It involved purposive sampling by e-mailing invitation letters to physicians and FHTs within the Greater Toronto Area, with the aim of acquiring a small sample for an in-depth qualitative study (Guest et al. 2006; Miles and Huberman 1994). Physicians interested in participating in the study responded to the invitation by contacting the first author (R.A.) by e-mail or telephone. In-person interviews were scheduled at a time and location most convenient to participants. Telephone interviews were offered to participants who indicated a preference for it.

Interviews were conducted by the first author (RA) and lasted 45-60 minutes. Each interview began with the interviewer reading an opening statement (see Table 1). Our intention was to enable participant-driven identification of incentives and disincentives within the broad framework provided as guidance. Interview questions were structured around four key 
areas of treatment for CMDs: identification and/or screening, pharmacological treatment, psychological treatment and collaborative care. The decision to frame our interview questions around these four key areas was inspired by the quality standards of care for depression and anxiety provided by the National Institute for Health and Care Excellence (NICE) (NICE 2011, 2014, 2016). Field notes were made immediately after completing each of the interviews. Written informed consent was obtained from each of the participants prior to the interview.

TABLE 1. Semi-structured interview guide Interviewer's opening statement prior to start of interview

"This interview is going to explore incentives and disincentives for the treatment of common mental disorders in Family Health Teams. Common mental disorders refer to depression and anxiety. Incentives are those things that encourage treatment, whereas, disincentives are those things that deter treatment."

Identification

- Please describe your experience in diagnosing and treating common mental disorders (CMDs).

- What challenges might discourage identification of CMDs in your Family Health Team (FHT)?

- What might help facilitate the identification of depression and/or anxiety in your FHT?

\section{Screening}

- Do you have any experience in screening for CMDs?

- What challenges might discourage screening of CMDs in your FHT?

- What might help increase screening for CMDs in your FHT?

Pharmacological treatments

- What is your experience in using pharmacological treatments for CMDs?

- What challenges might discourage you from using pharmacological treatments for CMDs?

- What might help you in providing pharmacological treatments for CMDs?

Psychological treatment by non-physicians

- Do you have any psychological treatment by non-physicians in your FHT?

- What challenges might discourage psychological treatment for CMDs by non-physicians in your FHT?

- What might help increase psychological treatment for CMDs by non-physicians in your FHT?

Collaborative care

- Do you have any experience with collaborative care in your FHT?

- What challenges might discourage collaborative care for CMDs in your FHT?

- What might help you in providing collaborative care for CMDs?

Interviews were audio-recorded and transcribed. Once transcription was complete, the transcribed document was reviewed to ensure it matched the audio-recorded interview. Each participant was assigned a code to protect anonymity and was sent a copy of their transcribed interview via e-mail to review and make changes wherever they felt it necessary. This was done to ensure that data was captured accurately and participants were able to delete any information that might compromise their confidentiality upon publication of findings.

Thematic analysis (Braun and Clarke 2006) was used to analyze the data. Data collection, transcription, coding and analysis were interrelated processes. Each transcript was read at least twice and the core concepts were identified (Miles and Huberman 1994). A preliminary coding scheme was developed after identifying the major themes. NVivo, a qualitative data analysis software, was used to help organize the data analysis. Recruitment stopped when no new themes were being identified from the transcripts. 


\section{Results}

Qualitative semi-structured interviews were conducted between June and August 2013. Invitational letters were e-mailed directly to $111 \mathrm{FHT}$ physicians and to the general e-mail address provided on the website of 33 FHTs who asked for it. The sample for this study consisted of the first 10 primary care physicians who responded to the invitation to participate. Sizes of FHTs varied from small to large. Three participants were from the same large FHT that had more than 60 physicians attached to it. The remaining seven participants were each from different FHTs. Six in-person interviews were conducted and four telephone interviews. Ten themes emerged from the data acting as incentives and/or disincentives influencing treatment of CMDs. With the exception of patient-centred care, each of the themes contains both incentives and disincentives for the treatment of CMDs. The 10 themes are: high service demands, clinical presentation, patient-centred care, patient attributes, education, physician attributes, organizational factors, access to mental health resources, psychiatry and physician payment model. Table 2 demonstrates the type of care that was discussed in relation to the emerging theme.

TABLE 2. Type of care for CMDs that is related to the identified incentive/disincentive theme

\begin{tabular}{|c|c|c|c|}
\hline Identification and screening & Pharmacological treatment & Psychological treatment & Collaborative care \\
\hline $\begin{array}{ll}\text { - } & \text { High service demands } \\
\text { - } & \text { Clinical presentation } \\
\text { - } & \text { Patient-centred care } \\
\text { - } & \text { Patient attributes } \\
\text { - } & \text { Education } \\
\text { - Physician attributes } \\
\text { - } \\
\text { - } \text { Prganizational } \\
\text { Phician payment model }\end{array}$ & $\begin{array}{ll}\text { - } & \text { Patient-centred care } \\
\text { - } & \text { Patient attributes } \\
\text { - } & \text { Education } \\
\text { - } & \text { Mental health resources } \\
\text { - } & \text { Psychiatry }\end{array}$ & $\begin{array}{l}\text { - Patient-centred care } \\
\text { - Patient attributes } \\
\text { - Mental health resources } \\
\text { - Psychiatry }\end{array}$ & $\begin{array}{l}\text { - Organizational } \\
\text { - } \quad \text { Mental health resources }\end{array}$ \\
\hline
\end{tabular}

\section{High service demands}

All participants described the identification of CMDs being relatively easy because of the frequency of patients presenting symptoms. "I see a lot of it in my practice ... Most of my patients at some point would have either anxiety or depression ... [It's] the commonest thing we treat here" (P9). Participants described CMDs as a core part of practice in primary care, yet all participants said that they struggled to meet the high service demands required to treat $\mathrm{CMDs}$, particularly with existing time constraints. Time restrictions impeded identification and ongoing treatment of CMDs. "I have to admit that I'm not going to dig, because I have 15 or 30 minutes ... it's a can of worms, worms that I can't get into" (P1).

\section{Clinical presentation}

Clinical presentation acted as an incentive: CMDs were considered easily identifiable, because the symptoms were clear and physicians were confident that patients would generally improve with treatment. On the contrary, participants found it challenging when their patients did not improve despite treatment. Clinical complexities can act as a disincentive as well: "There's ... people that we are missing that are not identifying depression or anxiety ... because we're blind to the fact that there's an underlying depression causing the problem, or there's other complexities that are making it difficult for us to identify, willingly or unwillingly" (P3). 


\section{Patient-centred care}

Patient preferences influence the course of treatment and participants emphasized wanting to be flexible so as to provide patients with their treatment of choice. All participants described the therapeutic relationship as an incentive for both the patient and the physician. "We have relationships with our patients so they feel comfortable coming and especially exposing their vulnerable side" (P5). The long-term therapeutic patient-physician relationship was described as particularly important for the identification and treatment of CMDs, as well as a motivator to meet the care needs of the patients. "I had known her for twenty years ... I had time limitations. But you can imagine, I made time for her" (P5).

\section{Patient attributes}

When patients were a good fit for the existing resources, this was considered a motivator for family physicians. But when they were not a good fit for the types of treatment available, this was a disincentive. A further disincentive was when patients were perceived to have lower levels of motivation for change.

\section{Education}

All participants believed that they were able to identify and provide short-term treatment for CMDs. "I feel very comfortable with short-term treatment, crisis intervention, stabilization" (P5). However, participants indicated that their training did not equip them for the long-term management of CMDs, treatment of complex patients with CMDs, nor the psychological counselling needs of patients with CMDs. Participants also raised concerns about moments in their education that they felt may contribute to stigmatization and act as a systemic deterrent for physicians, which may have a potential impact on one's practice. "I actually have a very distinct memory of the first time that I was on the ward and I heard my attending making fun of the patient after we left the room ... that is really problematic ... what you're saying in the implicit messages that you're giving to students" (P8).

\section{Physician attributes}

Participants described physician attitudes, beliefs, the desire to provide good patient care and confidence in their clinical abilities as a motivator for treatment. Yet participants expressed limitations to their scope of practice that act as a disincentive; for example, feeling less confident in situations where there might be co-morbidity or complexity. "[I'm] reasonably comfortable with first step augmentation but it sort of depends ... on how much co-morbidity and complexity there is" (P3). Participants also talked about how feeling overwhelmed acts as a disincentive to the identification of CMDs and reaching out to existing resources. "The unspoken disincentives ... I as a family doctor ... feel overwhelmed by some of the acute things" (P6). Another physician described how feeling overwhelmed as a result of personal life stressors can impact on care: "[When I] have gone through a period ... of deaths and illness in my family, I'm less likely to be looking for mental illness if it doesn't come up" (P1). 


\section{Organizational factors}

Organizational factors acting as incentives include culture, leadership, team relationships and electronic medical records (EMRs). An organizational culture acts as an incentive by setting organizational goals and priorities for care. "We made mental health one of our initial clinic priorities ... [and] decided that identification and optimization of treatment for depression should be the major thrust of what we do as a team" (P4). Another physician said that mental healthcare was "in the fabric" (P10) of their FHT. Participants also stressed the importance of formal and informal leadership within the FHT in order to implement collaborative care. EMRs helped facilitate communication between team members and provided an easy referral mechanism. EMRs helped facilitate care by having screening tools accessible, tracking patient changes and acting as a reminder to perform certain tasks during clinical encounters.

Interpersonal relationships with colleagues helped facilitate communication about patient care and helped physicians and the various team members understand each other's roles in relation to treatment for CMDs. Geographical co-location of health providers enhanced collegial relationships and facilitated access to psychological resources. Not being geographically co-located was described as a disincentive by limiting communication and collaborative care. "Being geographically distributed is a hindrance because it's hard to form a relationship with someone that you're not with" (P4). In some cases, this leads to limited collaboration and access to other health providers. Some physicians indicated that some health providers are underutilized because of a lack of awareness of roles.

\section{Access to mental health resources}

\section{INTERPROFESSIONAL HEALTH PROVIDERS}

Interprofessional health providers (IHPs) act as incentives for both patients and physicians. All participants described how FHTs have made mental healthcare providers, like pharmacists and social workers, available to patients in a way that was not there prior to FHTs. "It has opened up the whole context of being able to see a social worker for counselling that was never there before" (P7). IHPs improved pharmacotherapy treatment and access to psychological treatment. "An incentive is the pharmacist. We have pharmacist[s] on our team and they really help with the pharmacotherapy piece. They give physicians great confidence around complex problems" (P4). Participants stated that IHPs are an incentive, because the referral process is easy. Psychological resources are made accessible to patients without financial costs. IHPs help improve patient outcomes and the physician burden is decreased. "Since our mental team was added ... I don't have to deal with all of it on my own" (P6).

A disincentive to treatment exists when accessing FHT resources is difficult, because of growing waitlists that make it difficult for patients to get in to see a social worker or a mental health counsellor in a timely manner. "There's always more demand than we have supply in mental health services" (P6). All participants described the lack of case management and long-term psychological resources as problematic. 


\section{COMMUNITY-BASED RESOURCES}

Having patients with the financial means to access private counselling services was one way to help improve access to FHT resources for those without financial resources. However, all participants described accessing community resources as problematic, because of the lack of available counselling resources. "Trying to find counselling services in the community ... that are long-term and ... don't require insane waiting lists is basically impossible" (P8). Participants also talked about selective accessibility also being problematic. "They'll say ... if the patient doesn't have goals then we won't work on them ... It's usually a more subtle no. It sometimes doesn't recognize that this person can't set goals. Or can't clearly annunciate their goals ... There are still some challenges particularly around this area" (P3). Patient access to community resources was difficult unless they were in a crisis. Participants also indicated that patients who weren't considered a good fit for community services, because they were perceived as having a lower level of motivation, or considered more complex, have a much harder time accessing services.

All physicians described accessing community resources as a highly burdensome process that may deter treatment. "A lot of what used to be receptionist work has now gone to the doctors ... You actually still have to sit down and do it. For me that's not a problem, but [it is] for a lot of doctors" (P7). Another physician stated, "I don't have time to sit there and call people and find this out" (P9). Determining what resources are available was described as problematic. All participants described the referral process itself as being increasingly burdensome for physicians and a potential deterrent: "I have to admit, there's times that I look at the form and go, 'Ah, no!"' (P7). Participants indicated that they were less likely to pursue a referral if the process was burdensome.

All participants identified waitlists to community resources as a major deterrent to psychological treatment, and physicians may not pursue a referral if they know waitlists are long. Long wait times can also increase patient burden and distress. "When they learn that there are these long wait times, there's a sense of disbelief but also of anger ... I try to put it back to them, like, this actually is not my problem. So, how do you see yourself helping yourself?" (P3) Participants in this study indicated that a lack of access to community resources might result in greater use of drug therapy than if psychological resources were available. "Getting people onto pharmacological treatments ... I think unfortunately happens too often because people don't have access to counselling services" (P8). As a result, not having resources for psychotherapy becomes an incentive for drug therapy.

\section{Psychiatry}

All physicians identified easy access to psychiatry consultations whose flexible approach and personality were a good fit for their particular FHT as an incentive. "The other incentive ... is we have a consultant psychiatrist who works with us who we can speak to on the phone who provides indirect consultation to us ... Every time that I speak to her, I learn something new and then it lets me look after a whole bunch of other patients better" (P4). 
Participants also stated that patients in a crisis tended to have good access to psychiatry; yet, all participants considered limited and untimely access to psychiatry a disincentive. All participants talked about difficulties accessing psychiatry when a patient is not in an acute crisis. All participants also expressed concerns that psychiatry does not provide psychotherapy, longitudinal care or ongoing follow-ups. "They will diagnose the patient but they won't do the ongoing care ... I am very comfortable in the diagnosis state. What I'm not good at is treating ... but they will not keep the mood and anxiety disordered patients ... I am a short-term intervention ... beyond that, I really am looking for help" (P5).

\section{Physician payment model}

The physician payment model was identified as an incentive for treatment and can facilitate scheduling that is compatible for treating CMDs. "By far the number one thing that allows me to actually appropriately address the needs of this population is the payment model" (P8). Participants stated that payment models that support booking longer appointments, or are not reliant on how many people a physician sees in a day, are more aligned with providing good mental healthcare.

Physician remuneration can also act as a disincentive for treatment, because there is a lack of specific financial incentives for CMDs. The lack of financial incentives is problematic when financial incentives exist for other types of treatment. "What I'm incented to do in my practice by the government is to really look after really well my diabetics and my congestive heart failure patients using the flow sheet because I'm getting paid way more to look after those patients than anyone else. So, mental health does fall behind" (P4). Despite some of the previous benefits, participants indicated that physician payment models could also act as a disincentive for scheduling. Participants also indicated that physicians might not refer to some external resources even if there is a benefit for patients with CMDs, because there is a financial penalty built into the payment model. Participants indicated that a disincentive might exist when physician payment models do not take into account the higher levels of service required to treat patients with CMDs or patients with complex care needs. "There are patients that are over-using you as a resource and that is not reflected in the model ... I could pick some key people that are technically young and healthy as viewed by the government, but who really do use our resources A LOT. I would say that's not reflected well enough probably" (P2). Another physician stated: "There's definitely an incentive to not take complicated patients on because payments run the same so why would you take on the most complicated patients instead of the least complicated person? And certainly there is an incentive to take on the least complicated person" (P3).

\section{Discussion}

This study identified a broad range of incentives and disincentives that influence the treatment of CMDs. CMDs are a core part of practice in primary care, and with adequate training, physicians are able and confident in their abilities to identify and begin treatment. 
Effectively educating primary care physicians to better recognize and manage CMDs requires curriculum that stimulates attitudes, skills, as well as content knowledge (Gask 2013). Education to improve care for CMDs, however, is most effective when accompanied by other strategies, such as use of guidelines, consultations with psychiatrists, collaborations with case managers and organizational supports (Gilbody et al. 2003; Kroenke et al. 2000). Physicians in this study emphasized that they, and the culture of the FHTs they work in, view mental healthcare as important. Participants described how organizations that make mental healthcare an organizational priority imbed tools and resources so that physicians and other care providers can better meet the unique care needs required for CMDs. Further, participants also stressed that effectively treating CMDs requires more time and service than other types of health issues. Physician payment models and having easy access to a range of IHPs facilitates treatment for patients seeking care for CMDs in FHTs. However, high service demands, complex patients, organizational factors, limited access to psychological counselling and psychiatry, overwhelmed physicians and physician payment models are deterring treatment for CMDs.

Despite wanting to provide patient-centred care that is flexible and responsive to patient's individual needs, poor access for psychological resources makes it challenging. Long waitlists for psychological and psychiatric resources means that patients are not receiving optimal treatment for CMDs (Ivbijaro 2012; NICE 2011). Raine et al. (2005) demonstrated that limited professional relationships deterred referrals, transfer of patient care, increases physician burden, and reduces physicians' abilities to provide optimal care. Physicians in our study emphasized the importance of having relationships with psychiatry, and voiced expectations of psychiatry that they believe are not being met. Physicians in this study desire improved access to psychiatrists particularly with more intensive and longitudinal involvement. Limited access to resources such as psychology, social work and psychiatry may be increasing physician burden and detracting from the collaborative intention of the FHT model (MOHLTC 2004; Sherman et al. 2010). Despite being in a collaborative model, physicians described the personal impact of feeling overwhelmed, which is harmful to physicians and can negatively affect patient care (Fralick and Flegel 2014).

There is a strong association between physician payment models and the quality of clinical care (Conrad 2010; Custers et al. 2008; Enjolras 1999; Steel et al. 2007). FHTs' innovative physician payment model may be restricting intention of greater access to mental healthcare (MOHLTC 2009). Despite payment models helping facilitate scheduling and appointment bookings, the FHT's model's innovative payment model appears to be problematic for patients with CMDs. Financial incentives that are inclusive of various health conditions but exclude mental health can deter treatment for CMDs (Post et al. 2009). Disincentives exist in physician payment models that deter care for patients with complexity or CMDs, because they are believed to require more services than patients who are healthier (MOHLTC 2014; Sherman et al. 2010). Despite CMDs being easily treatable in primary care, disincentives may be deterring FHTs from achieving optimal integration of primary mental healthcare. 
Participants in this study indicated that they were providing quality treatment for patients with CMDs despite disincentives that existed. What this suggests is that the range of incentives and disincentives may interact, some having more influence than others do.

There are several limitations to this study. As a pilot study with a small sample, findings cannot be generalized. No two FHTs are alike, which means that the results from this study may or may not be relevant to FHTs other than those included in this study and poses some challenge to transferability of findings. Also, because the letter of invitation did include a statement describing the objective of this study, and participants voluntarily opted into this study, bias selection is possible. Thus, it is possible that the perspectives of the 10 physicians interviewed in this study may not be representative of all FHT physicians. Given that FHTs are a collaborative care model, only including physicians in the sample means that our study provides only one perspective. There are other healthcare providers within FHTs - such as nurses, social workers and pharmacists - whose perspectives on incentives and disincentives would be of benefit. This study presents only one perspective. We decided that interviewing FHT physicians is the best sample population to begin an investigation on incentives and disincentives. All FHTs include physicians; as well, the FHT model was designed around a physician-centred incentive model. This initial study with FHT physicians provides a foundation of knowledge to build on. Other healthcare provider and patient perspectives will enrich future studies investigating incentives and disincentives for the treatment of CMDs.

Despite the limitations, there are several benefits of this study. Although we are not able to draw conclusions from this study, it does help us explore some of the challenges that exist. Its qualitative approach provides breadth and richness to understanding the topic of incentives and disincentives in FHTs that currently does not exist (Miles and Huberman 1994). This study is the first to our knowledge that explores physicians' perspectives of incentives and disincentives for the treatment of CMDs in FHTs, and thus additional research is needed to guide quality care in this area.

Providing high-quality care for CMDs involves other professionals be involved and so, seeking a broad range of perspectives is necessary. Research that can provide comparative data to other healthcare provider perspectives will be valuable. To fully appreciate the complexity of the system of incentives affecting mental healthcare in FHTs, we recommend that future research seek to involve the perspectives of stakeholders beyond the clinical teams, such as other mental health providers in communities, professional associations and policy makers and service users. Given that the bulk of literature on primary care incentives focuses on single-provider models of care, future research is needed to generate knowledge about incentive models relevant for interprofessional primary care settings. Realigning incentive systems for interprofessional primary care contexts is necessary if optimal prevention and management of CMDs is going to be achieved in Canada (Dewa et al. 2001; Durbin et al. 2016; Mulvale et al. 2008; Rush et al. 2013; Steele et al. 2013). Understanding incentives and disincentives influencing care is essential in order to achieve greater integration and capacity for care (Ashcroft et al. 2014; Craven and Bland 2013). 


\section{Acknowledgements}

This research was supported by a fellowship in the Social Aetiology of Mental Illness (SAMI) training program, a Strategic Training Initiative in Health Research funded by the Canadian Institutes of Health Research (CIHR), based at the Centre for Addiction and Mental Health and the University of Toronto.

Correspondence may be directed to: Rachelle Ashcroft at rachelle.ashcroft@utoronto.ca.

\section{References}

Ashcroft, R. 2014. "Inadequate Performance Measures Affecting Practices, Organizations and Outcomes of Ontario's Family Health Teams." Healthcare Policy 10(1): 86-96.

Ashcroft, R., J. Silveira, B. Rush and K. McKenzie. 2014. "Incentives and Disincentives for the Treatment of Depression and Anxiety: A Scoping Review." Canadian Journal of Psychiatry 59(7): 385-92.

Biller-Andorno, N. and T. Lee. 2013. "Ethical Physician Incentives - From Carrots and Sticks to Shared Purpose." NEJM 368: 980-82.

Braun, V. and V. Clarke. 2006. "Using Thematic Analysis in Psychology." Qualitative Research in Psychology 3(2): 77-101.

Conrad, D. 2010. “Incentives for Health-Care Performance Improvement." In P. Smith, E. Mossialos, I. Papanicolas, et al., eds., Performance Measurement for Health System Improvement Experiences, Challenges, and Prospects. Cambridge, UK: Cambridge University Press.

Craven, M. and R. Bland. 2013. “Depression in Primary Care: Current and Future Challenges." Canadian Journal of Psychiatry 58(8): 442-48.

Cuijpers, P., A. Beekman and C. Reynolds. 2012. "Preventing Depression: a Global Priority.” JAMA 307: $1033-34$.

Custers, T., J. Hurley, N. Klazinga and A.D. Brown. 2008. "Selecting Effective Incentive Structures in Health Care: A Decision Framework to Support Health Care Purchasers in Finding the Right Incentives to Drive Performance." BMC Health Services Research 8: 66.

Dewa, C.S., J.S. Hoch and P. Goering. 2001. "Using Financial Incentives to Promote Shared Mental Health Care." Canadian Journal Psychiatry 46(6): 488-95.

Durbin, A., J. Durbin, J.M. Hensel and R. Deber. 2016. "Barriers and Enablers to Integrating Mental Health into Primary Care: A Policy Analysis." Journal of Behavioral Health Services and Research 43: 127-39.

Enjolras, B. 1999. Incentives. Welfare State and Disincentive Effects. Oslo, Norway: Forskningsstiftelsen Fafo. Ferrari, A.J., F.J. Charlson, R.E. Norman, S.B. Patten, G. Freedman, C.J. Murray et al. 2013. “Burden of Depressive Disorders by Country, Sex, Age, and Year: Findings from the Global Burden of Disease Study 2010." PLoS Medicine 10(11): e1001547.

Fralick, M. and K. Flegel. 2014. "Physician Burnout: Who Will Protect Us from Us?” CMAJ 186(10): 731.

Gask, L. 2013. “Educating Family Physicians to Recognize and Manage Depression: Where Are We Now?" Canadian Journal Psychiatry 58(8): 449-55.

Gilbody, S., P. Whitty, J. Grimshaw and R. Thomas. 2003. “Educational and Organizational Interventions to Improve the Management of Depression in Primary Care." JAMA 289(23): 3145-51.

Guest, G., A. Bunce and L. Johnson. 2006. "How many Interviews Are Enough? An Experiment with Data Saturation and Variability." Field Methods 18: 59-82.

Hutchison, B. and R. Glazier. 2013. “Ontario's Primary Care Reforms Have Transformed the Local Care Landscape, but a Plan is Needed for Ongoing Improvement." Health Affairs 32(4): 695-703.

Hutchison, B., J.F. Levesque, E. Strumpf and N. Coyle. 2011. "Primary Health Care in Canada: Systems in Motion." Milbank Quarterly 89(2): 256-88. 
Rachelle Ashcroft et al.

Ivbijaro, G. 2012. Companion to Primary Care Mental Health. London, UK: Wonca and Radcliffe.

Jenkins, R. and G. Strathdee. 2000. “The Integration of Mental Health Care with Primary Care." International Journal of Law Psychiatry 23: 277-91.

Katzman, M.A., P. Bleau, P. Blier, P. Chokka, K. Kjernisted, M. Van Ameringen et al. 2014. "Canadian Clinical Practice Guidelines for the Management of Anxiety, Posttraumatic Stress and Obsessive-compulsive Disorders." BMC Psychiatry 14(Suppl 1): S1.

Kroenke, K., A. Taylor-Vaisey, A. Dietrich and T. Oxman. 2000. "Interventions to Improve Provider Diagnosis and Treatment of Mental Disorders in Primary Care." Psychosomatics 41(1): 39-52.

Lepine, J.P. and M. Briley. 2011. "The Increasing Burden of Depression." Journal of Neuropsychiatric Disease and Treatment 7(Suppl 1):3-7.

Miles, M. and M. Huberman. 1994. Qualitative Data Analysis: an Expanded Sourcebook. Thousand Oaks, CA: Sage. Mohamoud, S., J.C. Sapag and A. Khenti. 2012. "Mental Health and Substance Use Problems in Primary Care: Local, National and International Perspectives." In A. Khenti, J.C. Sapag, S. Mohamoud and A. Ravindran, eds., Collaborative Mental Health: an Advanced Manual for Primary care Professionals. Toronto, ON: Centre for Addiction and Mental Health.

Mulvale, G., U. Danner and D. Pasic. 2008. "Advancing Community-Based Collaborative Mental Health Care through Interdisciplinary Family Health Teams in Ontario." Canadian Journal of Community Mental Health 27: 55-73.

National Institute for Health and Clinical Excellence (NICE). 2011. Common Mental Health Disorders: Identification and Pathways to Care. London, UK: Author.

National Institute for Health and Clinical Excellence (NICE). 2014. Anxiety Disorders: NICE Quality Standard. London, UK: Author. <https://www.nice.org.uk/guidance/qs53>.

National Institute for Health and Clinical Excellence (NICE). 2016. Depression in Adults: Recognition and Management. London, UK: Author. <https://www.nice.org.uk/guidance/cg90>.

Ontario Ministry of Health and Long-Term Care (MOHLTC). 2004. Family Health Teams - Advancing Primary Care. Toronto, ON: Author.

Ontario Ministry of Health and Long-Term Care (MOHLTC). 2005. Guide to Interdisciplinary Team Roles and Responsibilities. Toronto, ON: Author. <http://www.health.gov.on.ca/en/pro/programs/fht/docs/fht_ inter_team.pdf $>$.

Ontario Ministry of Health and Long-Term Care (MOHLTC). 2009. Guide to Physician Compensation. Toronto, ON: Author. <http://www.health.gov.on.ca/en/pro/programs/fht/docs/fht_compensation.pdf>.

Ontario Ministry of Health and Long-Term Care (MOHLTC). 2014. Family Health Teams. Toronto, ON: Author. <http://www.health.gov.on.ca/en/pro/programs/fht/>.

Post, E.P., A.M. Kilbourne, R.W. Bremer, F.X. Solano Jr., H.A. Pincus and C.F. Reynolds 3rd. 2009. "Organizational Factors and Depression Management in Community-Based Primary Care Settings." Implementation Science 4: 84.

Pottie, K., B. Farrell, S. Haydt, L. Dolovich, C. Sellors, N. Kennie et al. 2008. “Integrating Pharmacists into Family Practice Teams. Physicians' Perspectives on Collaborative Care." Canadian Family Physician 54: 1714-15.

Raine, R., S. Carter, T. Sensky and N. Black. 2005. "Referral into a Void': Opinions of General Practitioners and Others on Single Point of Access to Mental Health Care." Journal of the Royal Society of Medicine 98: 153-57.

Rush, B., C. McPherson-Doe, R.C. Behrooz and A. Cudmore. 2013. "Exploring Core Competencies for Mental Health and Addictions Work within a Family Health Team Setting." Mental Health in Family Medicine 10(2): 89-100.

Sherman, J., R. Pong, J.R. Swenson, M.G. Delmege, A. Rudnick, R.G. Cooke et al. 2010. Mental Health Services in Smaller Northern Ontario Communities: A Survey of Family Health Teams. Sudbury, ON: Laurentian University.

Steel, N., S. Maisey, A. Clark, R. Fleetcroft and A. Howe. 2007. "Quality of Clinical Primary Care and Targeted Incentive Payments: An Observational Study." British Journal of General Practice 57: 449-54.

Steele, L.S., A. Durbin, L.M. Sibley and R. Glazier. 2013. "Inclusion of Persons with Mental Illness in PatientCentred Medical Homes: Cross-Sectional Findings from Ontario, Canada." Open Medicine 7(1): e9-20. 